\title{
Metabolism of Phosphatidylcholine in Brain and Liver of Developing Rats
}

\author{
Nobukazu Chida and Tsuneo Arakawa \\ Department of Pediatrics, Tohoku University Shool of Medicine, Sendai
}

\begin{abstract}
Chida, N. and Arakawa, Ts. Metabolism of phosphatidylcholine in brain and liver of developing rats. Tohoku J. exp. Med., 1971, 104 (4), 359 371 - Incorporation of CDP-choline-1, 2-14 $\mathrm{C}$ into phosphatidylcholine by brain homogenate and microsome was found to be higher than that of liver before and during active myelination period in rats. Incorporation of $\mathrm{S}$-adenosylmethionine-methyl-14 $\mathrm{C}$ into phosphatidylcholine by brain microsome was about $1 / 20$ of that by liver microsome in two-week-old rats. These results indicate that in developing rat brain, phosphatidylcholine may be synthesized by transmethylation, to some extent, in addition to the major pathway via CDP-choline. —— phosphatidylcholine synthesis; brain; myelination
\end{abstract}

Phosphatidylcholine is widely distributed in both gray and white matter of the brain (McIlwain 1966). It is also known that phosphatidylcholine is one of the major components of membrane structure including myelin sheath (O'Brien 1965, Arakawa et al. 1969). At birth, brain is more than twice as large as liver in rat as well as in human (Nesbitt 1966), and undergoes rapid growth, associated with active lipid synthesis and myelin formation (Smith 1967, Cuzner and Davison 1968). It is suggested that a number of enzymes concerning lipid metabolism show an increase in their activity before and during active myelination period (McMurray 1964).

The purpose of this experiment was to study the in vivo and in vitro biosynthesis of phosphatidylcholine in developing rat brain with special reference to two major pathways:

(1) CDP-choline $+\mathrm{D}-\alpha, \beta$-diglyceride $\longrightarrow$ phosphatidylcholine (Kennedy and

Weiss 1956)

(CDP-choline: 1, 2-diglyceride choline phosphotransferase)

(2) phsophatidylethanolamine $+\mathrm{S}$-adenosyl-L-methionine

$\longrightarrow$ phsophatidylcholine (Bremer and Greenberg 1961, Bjørnstad and
Bremer 1966, Bremer et al. 1960, Bremer
and Greenberg 1960)

(Phosphatidylethanolamine: adenosylmethionine methyltransferase)

Received for publication, February 6, 1971. 


\section{Materials and Methods}

The Wistar strain rats were used in this expriment and fed on a standard diet purchased from the Oriental Co., Tokyo, Japan. L-methionine-methyl-14 $\mathrm{C}$ (specific activity $10.3 \mathrm{mCi} / \mathrm{mmole}$ ) and choline-methyl-14 $\mathrm{C}$ (specific activity $5.2 \mathrm{mCi} / \mathrm{mmole}$ ) were purchased from New England Nuclear Corp., Boston, Mass., U.S.A. Choline-methyl- ${ }^{8} \mathrm{H}$ (specific activity $6,700 \mathrm{mCi} / \mathrm{mmole}$ ) and methionine-methyl-14 ${ }^{14}$ (specific activity $56.8 \mathrm{mCi} / \mathrm{mmole}$ ) were obtained from Nuclear Chicago, U.S.A. S-adenosyl-L-methionine-methyl-14 $\mathrm{C}$ (specific activity $49 \mathrm{mCi} / \mathrm{mmole}$ ) was purchased from the Radiochemical Centre, Amersham, England. CDP-choline-1,2-14 $\mathrm{C}$ (specific activity $2.2 \mathrm{mCi} / \mathrm{mmole}$ ) was a gift from Takeda Chemical Co., Osaka, Japan.

In vivo studies: all radioactive materials were diluted with $0.9 \%$ saline and administered intraperitoneally (Bjфrnstad \& Bremer, 1966).

For a single tracer study, methionine-methyl-14 $\mathrm{C}$ or choline-methyl- ${ }^{14} \mathrm{C}$ was given intraperitoneally at a dose of $5 \mu \mathrm{Ci}$ per $20 \mathrm{~g}$ body weight. For a double tracer study, a mixture of methionine-methyl ${ }^{14} \mathrm{C}$ and choline-methyl- ${ }^{-3} \mathrm{H}$ (10:1 by radioactivity) was administered. Animals were killed by exsanguination, and organs were homogenized in a small volume of ice-cold water. Three volumes of $10 \%$ trichloroacetic acid (TCA) were added to the homogenate and mixed well and centrifuged. The precipitates were rinsed twice with three volumes of $5 \%$ TCA and centrifuged. Supernatants were combined and stored as "TCA soluble fraction".

Precipitates were extracted with a mixture of chloroform and methanol $(2: 1, v / v)$, and the lipid fraction was evaporated to dryness. Fractionation and purification of lipids were carried out by DEAE-cellulose column chromatography and thin layer chromatography (TLC), according to Rouser et al. (1965).

Spots on TLC plates were identified with standards (sphingomyelin, phosphatidylcholine, phosphatidylethanolamine, phosphatidylserine, phosphatidylinostiol, cerebroside, and sulfatide which were purchased from Applied Science Lab., U.S.A.), and scraped off into counting vials with $4 \%$ Cab-O-sil toluene scintillator according to Snyder and Stephens (1962) to measure radioactivity by means of Aloka Liquid Scintillation Counter, Type LSC601, Japan Radiation \& Medical Electronics, Inc. Tokyo, Japan. TCA soluble fractions were dried up under heating lamp, cooled and dissolved in $0.2 \mathrm{ml}$ of methanol and radioactivity was determined in Bray's solution (Bray 1960) using Aloka Liquid Scintillation Counter. For simultaneous determination of ${ }^{9} \mathrm{H}$ and ${ }^{14} \mathrm{C}$ activity in experiments in which both methionine-methyl ${ }^{14} \mathrm{C}$ and choline-methyl- ${ }^{3} \mathrm{H}$ were used, samples were treated in the same way as described above and radioactivity of ${ }^{3} \mathrm{H}$ and ${ }^{14} \mathrm{C}$ was determined by screenout method in Aloka Liquid Scintillation Counter.

In vitro studies: The microsome fractions were prepared according to Brady et al. (1965). The incubations were carried out in test tubes at $37^{\circ} \mathrm{C}$. Each tube contained $50 \mu$ moles of Tris buffer ( $\mathrm{PH} 8.0$ ), $10 \mu$ moles of $\mathrm{MgCl}_{4}, 5 \mu$ moles of reduced glutathione, $0.5 \mu \mathrm{Ci}$ of $\mathrm{CDP}$. choline-1,2-14C or S-adenosyl-L-methionine-methyll.14 $\mathrm{C}$ and $0.3 \mathrm{ml}$ of microsome fraction (about $20 \mathrm{mg}$ as protein) in $0.2 \mathrm{M}$ Tris buffer or $0.5 \mathrm{ml}$ of homogenate in $0.2 \mathrm{M}$ Tris buffer (PH 8.0) which was prepared by centrifugation at $1,000 \times \mathrm{g}$ for $10 \mathrm{~min}$. When methioninemethyl- ${ }^{14} \mathrm{C}$ was used instead of S-adenosyl-methionine-methyl-19 $\mathrm{C}, 10 \mu$ moles of ATP was also added to the incubation mixture described above, according to Gibson et al. (1961). At the end of incubation, the reaction was stopped by addition of 10 volumes of a mixture of chloroform and methanol $(2: 1, \mathrm{v} / \mathrm{v})$ and mixed well. Chloroform fraction was washed three times with $0.9 \%$ saline. Fractionation of phospholipids was done as described above. When S-adenosyl-L-meth.onine-methyl-14C was used, phosphatidylcholine was further hydrolized and choline was precipitated as the Reineckate salt. Decomposition of choline Reineckate and determination of radioactivity in choline moiety was carried out according to Bremer and Greenberg (1961). 


\section{Results}

In vivo incorporation of methionine-methyl-14C into brain and liver phosphatidylcholine: In 2-week-old rats a significant incorporation of methionine-methyl${ }^{14} \mathrm{C}$ into liver phosphatidylcholine was observed as early as 30 minutes after the intraperitoneal injection, this result being in agreement with others' results (Bjornstad

TABLE 1. Transport of methionine-methyl ${ }^{14} C$-into brain and incorporation of methionine-methyl-14C into phosphatidylcholine, phosphatidylethanolamine, and sphingomyelin of the brain and liver in 2-week-old rats. The radioactive material was injected intraperitoneally

\begin{tabular}{|c|c|c|c|c|c|c|}
\hline & \multirow{2}{*}{$\begin{array}{l}\text { Time after } \\
\text { injection }\end{array}$} & \multirow{2}{*}{$\begin{array}{c}\text { TCA soluble } \\
\text { fraction } \\
\text { cpm/100 mg } \\
\text { wet weight }\end{array}$} & \multicolumn{2}{|c|}{ Phosphatidylcholine } & \multirow{2}{*}{$\begin{array}{l}\text { Phosphati- } \\
\text { dylethano- } \\
\text { lamine } \\
\text { cmp/l00 mg } \\
\text { wet weight }\end{array}$} & \multirow{2}{*}{$\begin{array}{l}\text { Sphingo- } \\
\text { myelin } \\
\text { cpm/100 mg } \\
\text { wet weight }\end{array}$} \\
\hline & & & $\begin{array}{l}\mathrm{cpm} / 100 \mathrm{mg} \\
\text { wet weight }\end{array}$ & $\begin{array}{l}\text { epm } / 100 \% \\
\text { phorphorus }\end{array}$ & & \\
\hline 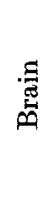 & 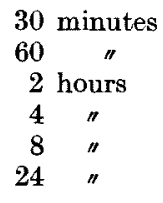 & $\begin{array}{l}2,141 \\
2,942 \\
2,358 \\
2,291 \\
2,139 \\
2,733\end{array}$ & $\begin{array}{r}73 \\
143 \\
\\
271 \\
693 \\
1,881\end{array}$ & $\begin{array}{r}146 \\
376 \\
\\
301 \\
778 \\
3,762\end{array}$ & $\begin{array}{r}3 \\
6 \\
5 \\
4 \\
40 \\
44\end{array}$ & $\begin{array}{r}2 \\
32 \\
76 \\
76 \\
71 \\
106\end{array}$ \\
\hline$\stackrel{5}{5}$ & $\begin{array}{c}30 \text { minutes } \\
60 " \text { " } \\
2 \text { hours } \\
4 \\
8 " ~ \\
24 "\end{array}$ & $\begin{array}{r}10,174 \\
11,992 \\
7,946 \\
8,694 \\
9,480 \\
7,590\end{array}$ & $\begin{array}{r}27,609 \\
23,098 \\
24,648 \\
24,724 \\
18,080 \\
4,356\end{array}$ & $\begin{array}{l}62,700 \\
56,336 \\
60,237 \\
50,457 \\
53,176 \\
15,725\end{array}$ & $\begin{array}{r}592 \\
258 \\
218 \\
102 \\
112 \\
56\end{array}$ & $\begin{array}{r}3,948 \\
3,738 \\
4,226 \\
2,948 \\
2,806 \\
9983\end{array}$ \\
\hline
\end{tabular}

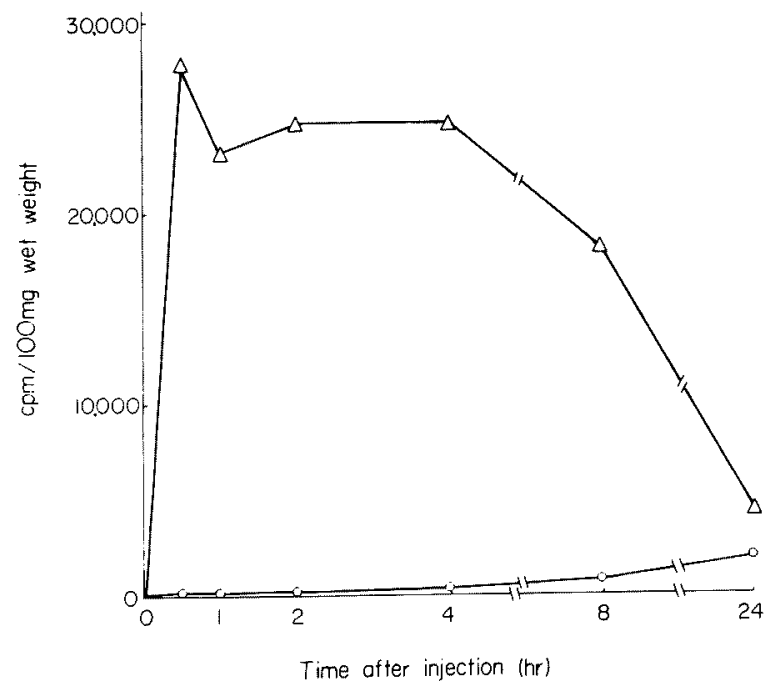

Fig. 1 Incorporation of methonine-methyl ${ }^{14} \mathrm{C}$ into liver and brain phosphatidylcholine in 2 week-old rats. The radioative material was injected intraperitoneally.

$\circ \longrightarrow$ Brain phosphatidylcholine $\triangle \longrightarrow$ Liver phosphatidylcholine 
and Bremer 1966) (Table 1, Fig. 1). The radioactivity of liver sphingomyelin was about $1 / 7$ of phosphatidylcholine. The radioactivity of TCA soluble fractions of brain, which are thought to represent roughly free methionine-methyl $-14 \mathrm{C}$, showed about 1/5 of those of livers, remaining constant, probably due to the regulation by blood brain barrier (Neame 1968).

Incorporation of methionine-methyl-14 $\mathrm{C}$ into brain phosphatidylcholine was very low soon after the injection, but increased steadily to about $1 / 2$ of liver phosphatidylcholine one day after the injection.

In vivo incorporation of choline-methyl-14C into brain phosphatidylcholine: The radioactive material was injected intraperitoneally into 2 -week-old rats and time courses for the choline-methyl ${ }^{14} \mathrm{C}$ incorporation into brain and liver phosphatidylcholine are shown in Table 2 and Fig. 2. Maximum specific activity of liver

TABLE 2. Transport of choline-methyl-14 $C$ into brain and incorporation week-old rats (the radioactive material

\begin{tabular}{c|c|c|c|}
\hline \multirow{2}{*}{ Time aftere injection } & \multicolumn{2}{|c|}{ Serum } & \\
\cline { 2 - 4 } & $\begin{array}{c}\text { TCA soluble } \\
\text { fraction cpm/ml }\end{array}$ & $\begin{array}{c}\text { Phosphatidylcholine } \\
\text { cpm/ml }\end{array}$ & $\begin{array}{c}\text { TCA soluble fraction } \\
\text { cpm/whole brain }\end{array}$ \\
\hline 15 minutes & 91,580 & 93 & 2,510 \\
$30 "$ " & 77,144 & 252 & 2,820 \\
20 & 72,244 & 626 & 2,793 \\
4 hours & 78,444 & 9,288 & 2,631 \\
8 " & 51,026 & 7,686 & 2,570 \\
$24 "$ & 62,200 & 17,834 & 3,666 \\
3 days & 40,200 & 3,834 & 2,692 \\
& 9,956 & 3,448 & 2,412 \\
& 10,250 & 4,950 & 2,377
\end{tabular}

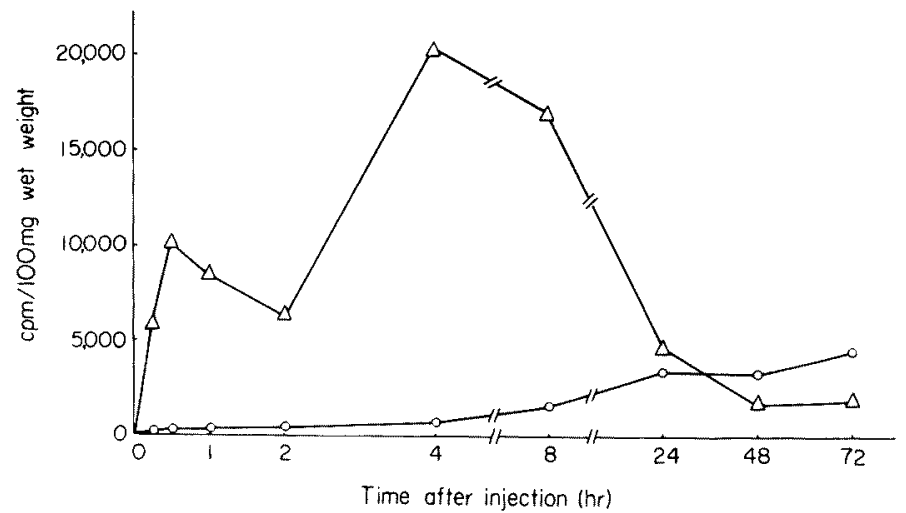

Fig. 2. Incorporation of choline-methyl-14C into liver and brain phosphatidylcholine in 2 -weeks-old rats. The radioactive material was injected intraperitoneally. 
phosphatidylcholine was found about 4 hours after the injection. A rapid equillibration of liver and plasma phosphatidylcholine has been reported to take place (Bjcrnstad and Bremer 1966). In our present experiment maximum radioactivity of serum phosphatidylcholine was found about one hour after that of liver phosphatidylcholine. Radioactivity of the TCA soluble fraction of brain, which was thought to be due mostly to free choline-methyl-14 $\mathrm{C}$, was far less than that of serum, but in similarity with the case with methionine-methyl- ${ }^{14} \mathrm{C}$, the level of the radioactivity in brain remained almost constant, indicating the possible regulation by blood brain barrier.

Radioactivity of brain phosphatidylcholine increased steadily after the cholinemethyl-14 $\mathrm{C}$ administration in terms of both specific activity and radioactivity per tissue wet weight. Liver phosphatidylcholine, on the other hand, decreased rapidly in radioactivity 8 hours after the injection, getting close to that of brain

of choline-methyl-14C into brain- and liver-phosphatidylcholine of twowas injected intraperitoneally)

\begin{tabular}{|c|c|c|c|}
\hline \multicolumn{2}{|l|}{ Brain } & \multicolumn{2}{|c|}{ Liver } \\
\hline \multicolumn{2}{|c|}{ Phosphatidylcholine } & \multicolumn{2}{|c|}{ Phosphatidylcholine } \\
\hline $\begin{array}{l}\text { cpm/100 mg } \\
\text { wet weight }\end{array}$ & cpm/100 $\gamma$ phosphorus & $\begin{array}{l}\mathrm{cpm} / 100 \mathrm{mg} \\
\text { wet weight }\end{array}$ & $\mathrm{cpm} / 100 \gamma$ phosphorus \\
\hline 198 & 95 & 5,951 & 13,391 \\
\hline 217 & 129 & 10,518 & 8,347 \\
\hline 315 & 216 & 8,483 & 22,577 \\
\hline 391 & 272 & 6,153 & 26,000 \\
\hline 727 & 478 & 20,350 & 37,779 \\
\hline 1,589 & 986 & 15,980 & 29,134 \\
\hline 3,245 & 1,602 & 4,771 & 8,849 \\
\hline 3,120 & 1,928 & 1,793 & 3,804 \\
\hline 4,473 & 2,188 & 1,990 & 4,265 \\
\hline
\end{tabular}

TABLE 3. Incorporation of CDP-choline-1, $2{ }^{14} \mathrm{C}$ into phosphatidylcholine by microsome from brain and liver of 2-week-old rats

\begin{tabular}{l|r}
\hline & cpm/10 mg protein \\
\hline Intact brain microsome fraction & 112,372 \\
Boiled brain microsome fraction & 136 \\
Intact liver microsome fraction & 91,780 \\
Boiled liver microsome fraction & 2,458
\end{tabular}

phosphatidylcholine, as is shown in Table 2.

Incorporation of CDP-choline-1,2-1 ${ }^{4} \mathrm{C}$ into phosphatidylcholine: Brain microsome fractions or homogenates were found to have as high activity as in liver microsome fractions or homogenates. Fetus (19 days gestation) and one to two week-old rats showed higher activities in brain than in liver. The activity increased after birth, showing a peak at two weeks after birth and declining slowly thereafter as 
TABLE 4. Incorporation of CDP-choline-1, $2 .{ }^{14} \mathrm{C}$ into phosphatidylcholine by brain and liver microsome fractions of rats with various age groups

\begin{tabular}{c|c|c}
\hline \multirow{2}{*}{ Age of animal } & $\begin{array}{c}\text { Brain } \\
\text { cpm/10 mg protein }\end{array}$ & $\begin{array}{c}\text { Liver } \\
\text { cpm/10 mg protein }\end{array}$ \\
\hline Fetus (19 days gestation) & 85,908 & $\mathbf{7 4 , 6 6 8}$ \\
2 weeks of life & 79,162 & 67,319 \\
$"$ " & 112,372 & 91,780 \\
3 weeks of life & 131,083 & 80,313 \\
$"$ " & 222,014 & \\
Adult" & 74,692 & \\
$"$ & 65,493 & \\
$"$ & 83,571 & \\
& 56,184 & \\
& 40,388 & \\
\end{tabular}

TABLE 5. Incorporation of CDP-choline-1, 2-14C into phosphatidylcholine by brainand liver-homogenates of rats with various age groups

\begin{tabular}{c|c|c}
\hline Age of animal & $\begin{array}{c}\text { Brain } \\
\text { cpm/10 mg protein }\end{array}$ & $\begin{array}{c}\text { Liver } \\
\mathrm{cpm} / 10 \mathrm{mg} \text { protein }\end{array}$ \\
\hline 4 days & 64,144 & 29,370 \\
2 weeks & 26,482 & 20,857 \\
4 weeks & 28,418 & 17,817 \\
$"$ Adult & 16,474 & 19,277 \\
$"$ & 21,914 & 12,425 \\
$"$ & 6,827 & 18,152 \\
$"$ & 12,157 & 18,548 \\
& & 9,591
\end{tabular}

shown in Tables 3, 4 and 5. McMurray (1964) reported that CDP-choline was actively incorporated into alkali-labile phospholipids by brain homogenate of developing rats, although they did not purify phosphatidylcholine. Our present data are in fairly good agreement with theirs.

Incorporation of S-adenosylmethionine-methyl-14 $\mathrm{C}$ or methionine-methyl-14C into phosphatidylcholine by brain microsome or homogenate: Time course of the phosphatidylcholine formation from S-adenosylmenthionine by rat brain microsome is shown in Fig. 3. In Table 6 was shown the incorporation of S-adenosylmethionine-methyl${ }^{14} \mathrm{C}$ into phosphatidylcholine and choline moiety by intact and boiled microsome fraction of brain and liver of two-week-old rats. Brain microsome fraction showed about $1 / 20$ of activity of liver microsome. S-adenosylmethionine incorporation was investigated using fetus (19 days gestation), one-, two- and three-week-old rats and adult rats (Table 7). Relatively high incorporation rates were seen in oneand two-week-old rats as compared to fetus and adults.

Similar results were obtained in the methionine incorporation into phosphatidylcholine by brain- and liver-homogenates as shown in Table 8. 


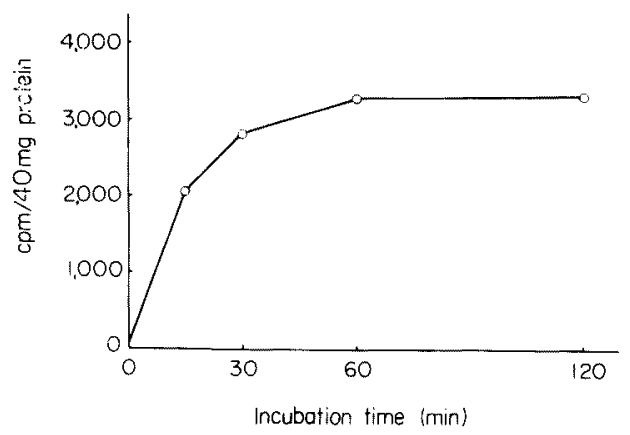

Fig. 3. Time course for incorporation of S-adenosylmethionine-methyl-14 $\mathrm{C}$ into phosphatidylcholine by brain microsome fraction of 2 -week-old rats.

TABLE 6. Incorporation of S-adenosylmethionine-methyl-14C into phosphatidylcholine and choline by microsome fractions of liver and brain of 2-week-old rats

\begin{tabular}{c|c|c}
\hline & $\begin{array}{c}\text { Phosphatidylcholine } \\
\text { cpm/15 mg protein }\end{array}$ & $\begin{array}{c}\text { Choline } \\
\text { cpm/15 mg protein }\end{array}$ \\
\hline Intact brain microsome fraction & 862 & 690 \\
Boiled brain microsome fraction & 378 & 290 \\
Intact liver microsome fraction & 11,278 & 9,764 \\
Boiled liver microsome fraction & 230 & 173
\end{tabular}

TABLE 7. Incorporation of $S$-adenosylmethionine-methyl-14C into phosphatidylcholine by brain-and liver-microsome fractions in rats with various age groups

\begin{tabular}{c|c|c}
\hline Age of animal & $\begin{array}{c}\text { Brain } \\
\mathrm{cpm} / 10 \mathrm{mg} \text { protein }\end{array}$ & $\begin{array}{c}\text { Liver } \\
\mathrm{cpm} / 10 \mathrm{mg} \text { protein }\end{array}$ \\
\hline Fetus (19 days gestation) & 147 & \\
1 week of life & 163 & 17,276 \\
$"$ " & 216 & \\
2 weeks of life & 924 & 14,699 \\
$"$ " & 882 & 18,621 \\
Adult & 695 & \\
$"$ " & 574 & \\
& 733 & \\
& 501 & \\
\end{tabular}

In vivo incorporation of methionine-methyl- ${ }^{14} \mathrm{C}$ into whole brain phosphatidylcholine: Incorporation of methionine-methyl ${ }^{14} \mathrm{C}$ into whole brain phosphatidylcholine was compared with that of whole liver phosphatidylcholine at various stages of development (Fig. 4.)

$$
\mathrm{N}=\frac{\text { Radioactivity of whole hrain phosphatidylcholine }}{\text { Radioactivity of whole liver phosphatidylcholine }} \times 100
$$

The $\mathrm{N}$ values at 2 hours after the methionine-methyl- ${ }^{14} \mathrm{C}$ injection were significantly 
TABLE 8. Incorporation of methionine-methyl-14C into phosphstidylcholine by brainand liver-homogenates in rats with various age groups

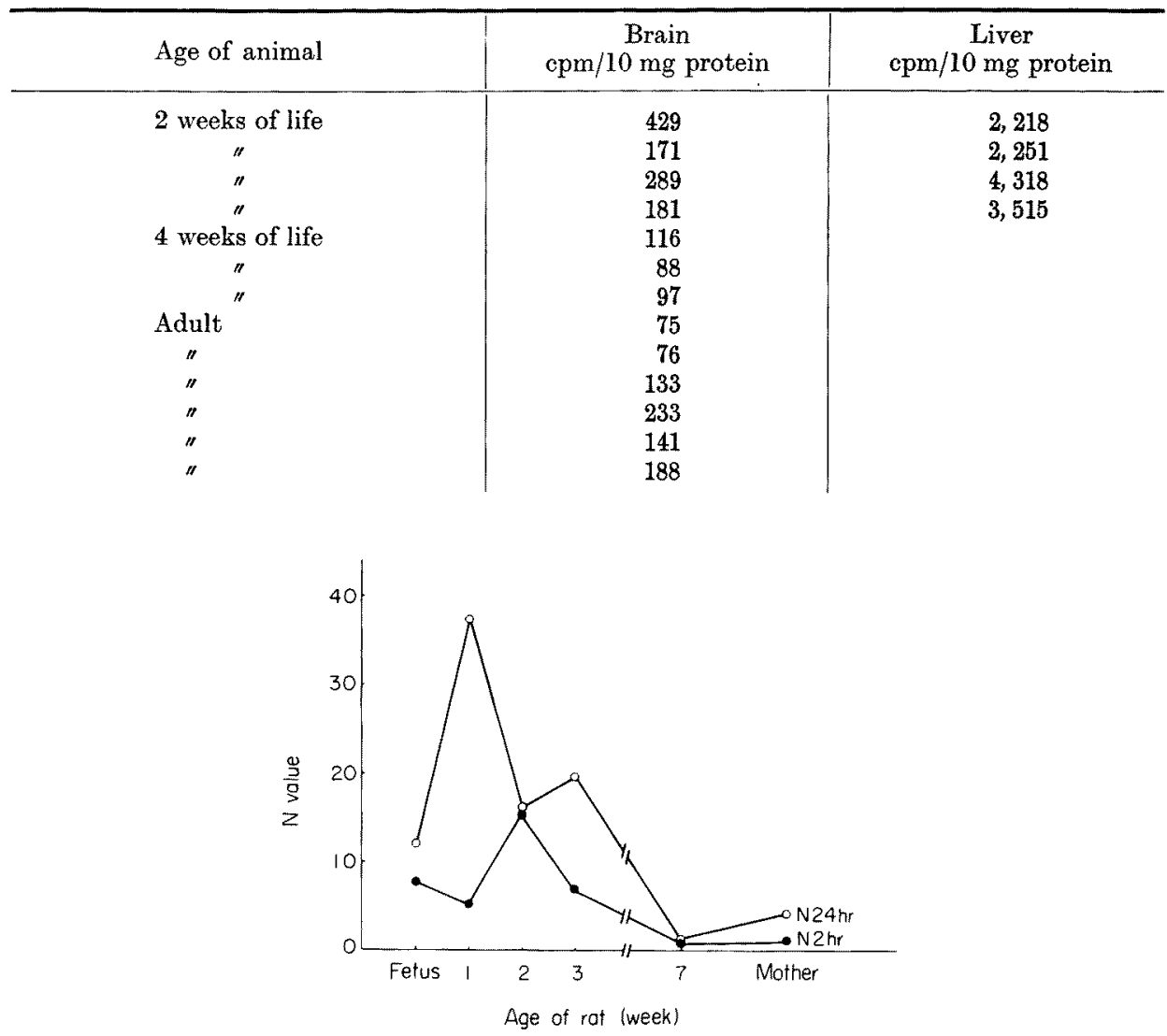

Fig. 4. Comparison between incorporation of methionine-methyl-14 $\mathrm{C}$ into whole brain phosphatidylcholine and that into whole liver phosphatidylcholine in rats with various age groups. The radioactive material was injected intraperitoneally.

$$
\mathrm{N}=\frac{\text { Radioactivity of whole brain phosphatidylcholine }}{\text { Radioactivity of whole liver phosphatidylcholine }} \times 100
$$

- - $\mathrm{N}$ at 2 hours after administration o- $\mathrm{N}$ at 24 hours after administration

higher in fetus and suckling rats of one- to three-week-old as compared to mature ones, indicating that much larger amounts of methionine were utilized for phosphatidylcholine synthesis in suckling rats than in adults.

In vivo incorporation of simultaneously injected methionine-methyl-14C and choline-methyl- ${ }^{3} \mathrm{H}$ into brain- and liver-phosphatidylcholine: Both the radioactive materials were injected intraperitoneally into rats of 21 days gestation. Time curves of ${ }^{3} \mathrm{H} /{ }^{14} \mathrm{C}$ of phosphatidylcholine for pregnant mother and fetus are shown in Fig. 5. ${ }^{3} \mathrm{H} /{ }^{14} \mathrm{C}$ of brain phosphatidylcholine of mother was remarkably high, indicating that major pathway of phosphatidylcholine synthesis in mother brain 


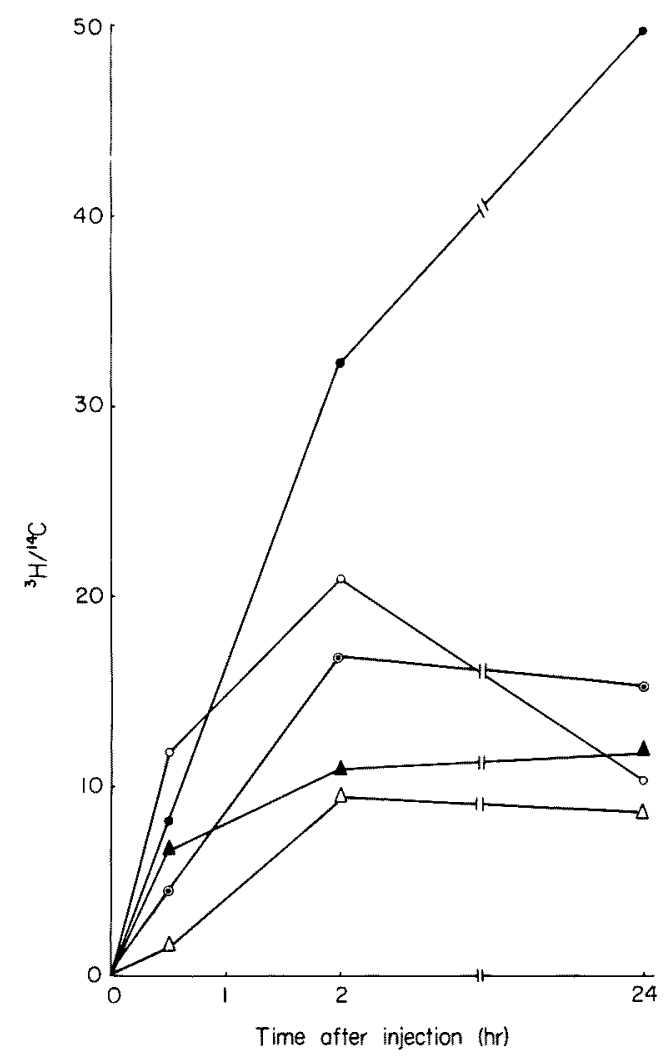

Fig. 5. Choline-methyl- ${ }^{3} \mathrm{H}$ and methionine-methyl-14 $\mathrm{C}$ were injected simultaneously into a rat of 21 days gestation, The ratio of ${ }^{3} \mathrm{H}$ to ${ }^{14} \mathrm{C}$ of phosphatidylcholine was examined on serum of the pregnant rat and on brain, and liver of the dam and fetus.

$$
\begin{aligned}
{ }^{3} \mathrm{H} /{ }^{14} \mathrm{C} & =\frac{{ }^{3} \mathrm{H} \text { of phosphatidylcholine }}{{ }^{14} \mathrm{C} \text { of phosphatidylcholine }} \\
& -\quad \text { Fetal brain } \\
& \text { Maternal serum }
\end{aligned}
$$

$\triangle \longrightarrow$ Fetal liver

- - Maternal brain

is via CDP-choline pathway. In fetus, on the other hand, ${ }^{3} \mathrm{H} /{ }^{14} \mathrm{C}$ was relatively low as compared to their mothers.

Relatively low ${ }^{3} \mathrm{H} /{ }^{14} \mathrm{C}$ was found in one- or two-week-old "ats (Fig. 6).

\section{Discussion}

It has been known that entry of amino acids into brain is under control of blood brain barrier (Neame 1968). Our data on the transport of methionine into brain are in good agreement with the concept. The present experiment also showed that the transport of choline into brain was, similarly to methionine, remarkably restricted, indicating that choline transport was also under a sort of control of blood brain barrier in developing rat brain as well as in mature ones. 


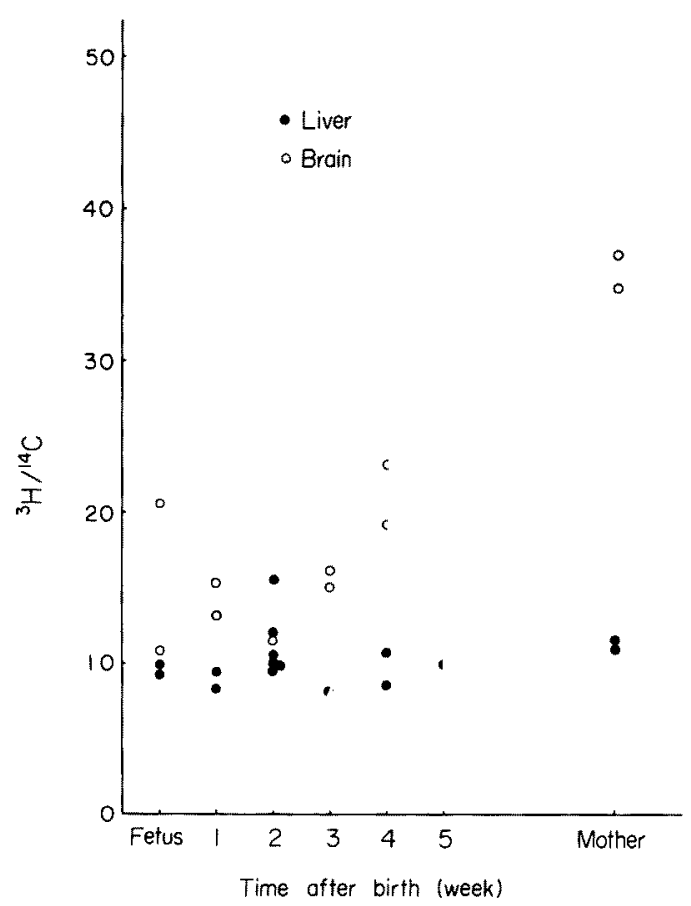

Fig. 6. Choline-methyl ${ }^{3} \mathrm{H}$ and methionine-methyl ${ }^{1{ }^{4} \mathrm{C}}$ were injected simultaneously into rats with various age groups, including a rat of 21 -day gestation. The radioactivity of phosphatidylcholine was estimated 2 hours after the injection.

$$
{ }^{8} \mathrm{H} /{ }^{14} \mathrm{C}=\frac{{ }^{3} \mathrm{H} \text { of phosphatidylcholine }}{{ }^{14} \mathrm{C} \text { of phosphatidylcholine }}
$$

Methionine was poorly incorporated into brain phosphatidylcholine, the result being similar to the results of extrahepatic tissues by other investigators (Bjornstad and Bremer 1966). However, relatively large amounts of methionine were incorporated into brain phosphatidylcholine before and during the active myelination period. There are two possible explanations for this phenomenon: (a) In young rats, entry of amino acids into brain are thought to be less restricted than in mature ones because of incomplete blood brain barrier. Thus more methionine will enter brain to be utilized for phosphatidylcholine synthesis as discussed below. (b) Intact phosphatidylcholine which was synthesized by transmethylation in liver might have entered brain through incomplete blood brain barrier in young rats.

'Two pathways are known for the de novo snythesis of phosphatidylcholine: A) Conversion of phosphatidylethanolamine to phosphatidylcholine by a stepwise methylation (Bremer 1961). B) Incorporation of choline into phosphatidylcholine via phosphorylcholine and CDP-choline (Kennedy and Weiss 1956).

Pathway $A$ is known to be very active in liver but far less active in extrahepatic tissue (Bremer and Greenberg 1961, Bjornstad and Bremer 1966, Marshall et al. 1965). In our experiment, pathway B was very active in brain 
of growing rats. The activity increased after birth with a peak at about two weeks after birth and declined slightly thereafter, in agreement with McMurray (1964). It is noteworthy that, in developing rats, both homogenate and microsome of brain showed higher activity in pathway $B$ than those of liver. In spite of the high incorporation of CDP-choline into phosphatidylcholine in vitro, in vivo incorporation of choline into brain phosphatidylcholine was found to be far less than that in liver probably because transport of choline into brain is restricted, similarly to methionine. On the other hand, an active in vivo incorporation of choline into brain phosphatidylcholine was reported by Ansell and Spanner (1968). However, in their experiment, choline was administered directly intracranially by-passing blood brain barrier, whereas in our experiment, radioactive choline was given intraperitoneally.

The present experiment also showed that the in vitro methionine incorporation into phosphatidylcholine by brain homogenate or microsome was significantly low in adult rats and this finding was in agreement with other investigators' results (Bremer and Greenberg 1961, Marshall et al. 1965). In contrast to mature ones, in vitro methonine incorporiation was relatively high in young rats, suggesting that phosphatidylcholine may be synthesized via Bremers' pathway (Bremer and Greenberg 1961) to some extent, in addition to Kennedy's (1956) at least before and during the active myelination period. Results obtained by the double tracer study using choline-methyl- ${ }^{3} \mathrm{H}$ and methionine-methyl- ${ }^{14} \mathrm{C}$ in vivo in our present experiment seem to support this possibility.

\section{Conclusion}

Phosphatidylcholine biosynthesis in developing rat brain was studied in vivo and in vitro. Transport of choline into brain was, similarly to that of methionine, found to be remarkably restricted, probably due to the regulation by blood brain barrier. Radioactivity of brain phosphatidylcholine after the intraperitoneal injection of methionine-methyl-14 $\mathrm{C}$ was very low for the first several hours and then continued to increase slowly, while that of liver phosphatidylcholine was remarkably high soon after injection, declining thereafter. The mode of in vivo incorporation of choline into brain phosphatidylcholine was very similar to that of methionine; it was very low soon after administration, but increased steadily, getting close to that of liver phosphatidylcholine one day after.

In vitro incorporation of S-adenosylmethionine-methyl-14 $\mathrm{C}$ into phosphatidylcholine by brain microsome was about $1 / 20$ of that by liver microsome in twoweek-old rats. Relatively high rate of methionine incorporation, though far less than that of liver, was observed in one- and two-week-old rats as compared to mature ones.

Incorporation of CDP-choline-1,2-14 $\mathrm{C}$ into phosphatidylcholine by brain homogenate or microsome fraction was remarkably high; the activity was found to be higher than that with liver before and during the active myelination period. 
Simultaneous administration of choline-methyl- ${ }^{3} \mathrm{H}$ and methionine-methyl-14 $\mathrm{C}$ was performed in different age groups with the aim to evaluate the two pathways of phosphatidylcholine biosynthesis: (1) CDP-choline $+\mathrm{D}$ - $\alpha, \beta$-diglyceride $\longrightarrow$ phosphatidylcholine and (2) phosphatidylethanolamine + S-adenosyl-L-methionine $\longrightarrow$ phosphatidylcholine. ${ }^{3} \mathrm{H} /{ }^{14} \mathrm{C}$ of liver phosphatidylcholine was almost constant, showing no significant differences among different age groups. In brain, however, ${ }^{3} \mathrm{H} /{ }^{14} \mathrm{C}$ was low in fetus and suckling rats as compared to that in mature ones. These results indicate that, in developing rat brain, phosphatidylcholine may be synthesized by transmethylation to some extent, in addition to the major pathway via CDP-choline.

\section{References}

1) Ansell, G.B. \& Spanner, S. The metabolism of ${ }^{14} \mathrm{C}$-labelled choline and phosphorylcholine in the brain of the rat in vivo. Biochem. J., 1968, 106, 20-21.

2) Arakawa, Ts., Mizuno, T., Chida, N. \& Narisawa, K. Electroencephalogram and myelin lipids of six-week-old rats with aminopterin-treatment during suckling period. Tohoku J. exp. Med., 1969, 99, 59-64.

3) Bjprnstad, P. \& Bremer, J. In vivo studies on pathways for the biosynthesis of lecithin in the rat. J. Lipid Res., 1966, 7, 38-45.

4) Brady, R.O., Bradley, R.M., Young, O.M. \& Kallor, H. An alternative pathway for the enzymatic synthesis of sphingomyelin. J. biol. Chem., 1965, 240, PC 3692.

5) Bray, G.A. A simple efficient liquid scintillator for counting aqueous solutions in a liquid scintillation counter. Analyt. Biochem., 1960, 1, 279-285.

6) Bremer, J., Figard, H. \& Greenberg, D.M. The biosynthesis of choline and its relation to phospholipid metabolism. Biochim. biophys. Acta, 1960, 43, 477-488.

7) Bremer, J. \& Greenberg, D.M. Biosynthesis of choline in vitro. Biochim. biophys. Acta, 1960, 37, 173-175.

8) Bremer, J. \& Greenberg, D.M. Methyl transfering enzyme system of microsomes in the biosynthesis of lecithin. Biochim. biophys. Acta, 1961, 46, 205-216.

9) Cuzner, M.L. \& Davison, A.N. The lipid composition of rat brain myelin and subcellular fractions during development. Biochem. J., 1968, 106, 29-34.

10) Gibson, K.D., Wilson, J.D. \& Udenfriend, S. The enzymatic conversion of phospholipid ethanolamine to phospholipid choline in rat liver. J. biol. Chem., 1961, 236, 673-679.

11) Kennedy, E.P. \& Weiss, S.B. The function of cytidine coenzymes in the biosynthesis of phospholipids. J. biol. Chem., 1956, 222, 193-214.

12) Marshall, E.F., Chojnacki, T. \& Ansell, G.B. The methylation of ${ }^{32} \mathrm{P} j$ phosphatidylmonomethylaminoethanol by S-adenosyl-L- $\left[\mathrm{Me}^{14} \mathrm{C}\right]$ methionine in liver preparations. Biochem. J., 1965, 95, 30-31.

13) Mellwain, H. In: Biochemistry and the Central Nervous System. J. \& A. Churchill Ltd., 104 Gloucester Place, London, 1966, pp. 197-212.

14) McMurray, W.C. Metabolism of phosphatides in developing rat brain-1. Incorporation of radioactive precursors. J. Neurochem., 1964, 11, 287-299.

15) Neame, K.D. Transport, metabolism and pharmacology of amino acids in brain. In: Applied Neurochemistry, ed. by A.N. Davison \& J. Dobbing, Black Well Scientific Publications, Oxford \& Edinburgh, 1968, pp. 119-177.

16) Nesbitt, R.E.L., Jr. Perinatal Development, In: Human Development, ed. by F. Falkner, Saunders, Philadelphia \& London, 1966, pp. 123-149.

17) O'Brien, J.S. Stability of the myelin membrane. Science, 1965, 147, 1099-1107.

18) Rouser, G., Galli, C. \& Kritchevsky, (*. Lipid composition of normal human brain and variations in metachromatic dystrophy, Tay-Sacks, Nieman-Pick, chronic Gaucher's and Alzheimer's disease. J. Amer. Oil Chemists' Soc., 1965, 42, 404-410. 
19) Smith, M.E. The metabolism of myelin lipids. In: Advances in Lipid Research, ed. by Paoletti, R. \& Kritchevsky, D. Vol. 5, Academic Press., New York \& London, 1967, pp. 241-278.

20) Snyder, F. \& Stephens, N. Quantitative carbon-14 and tritium assay of thin-layer chromatography plates. Analyt. Biochem., 1962, 4, 128-131. 